\title{
Wound Myiasis in a Patient with Squamous Cell Carcinoma
}

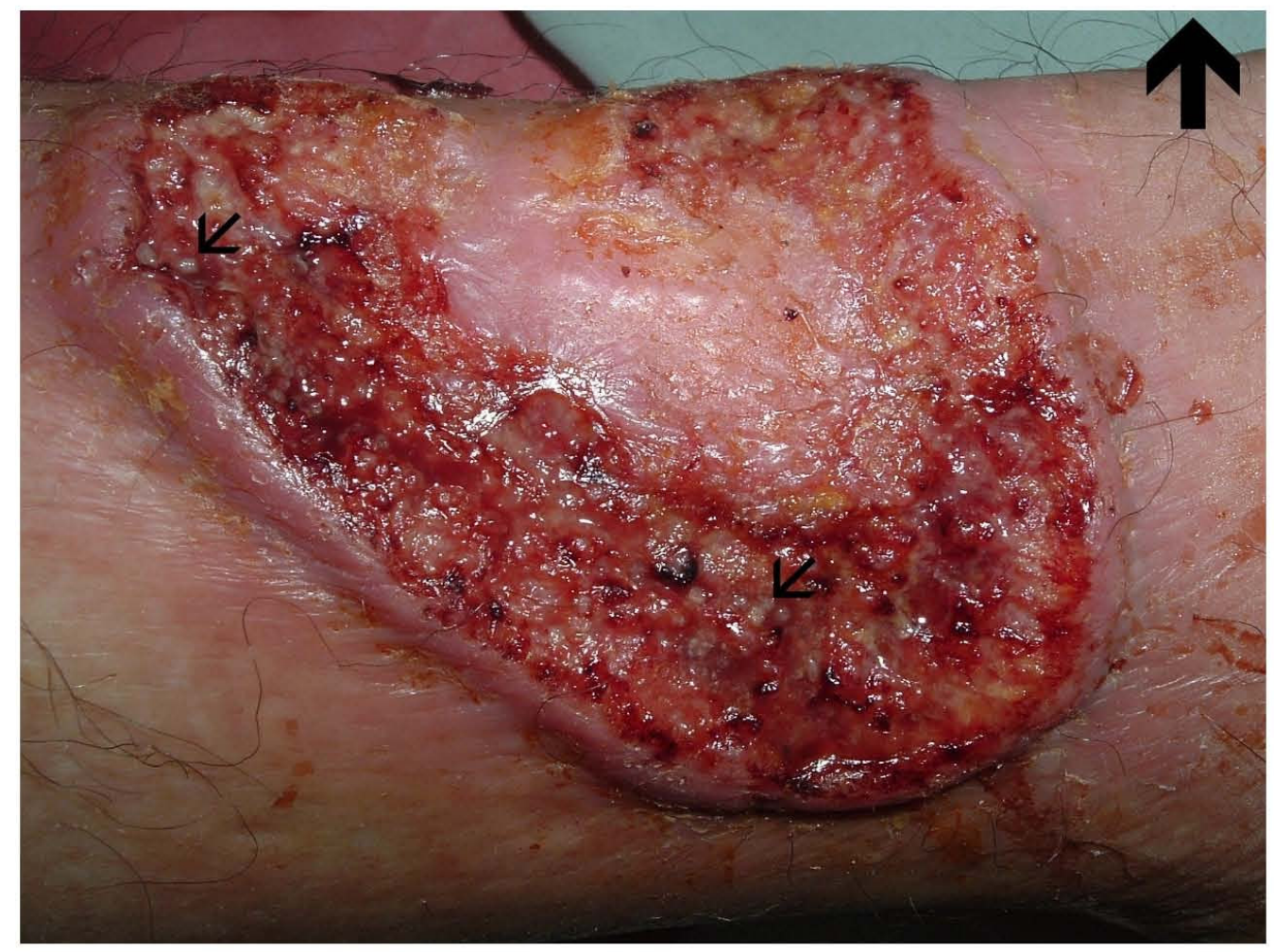

FIGURE 1. Large ulcer on lower right leg.

Mohammad Reza Namazi ${ }^{1}$ and Mohammad Kazem Fallahzadeh ${ }^{2, *}$ ${ }^{1}$ Dermatology Department, Faghihi Hospital, Shiraz, Iran; ${ }^{2}$ Medicinal and Natural Products Chemistry Research Center and Dermatology Department, Shiraz University of Medical Sciences, Shiraz, Iran

E-mail: Namazi mr@yahoo.com; kazem.fa@gmail.com *

Received September 25, 2009; Revised October 16, 2009; Accepted October 19, 2009; Published November 1, 2009

KEYWORDS: myiasis, wound, treatment

A 60-year-old, otherwise healthy, male farmer presented to the Dermatology Department with a large ulcer on his lower right leg. The lesion had started as a small papule 6 months before, which became eroded and transformed into a rather rapidly progressive ulcer. On careful inspection, numerous larvae 


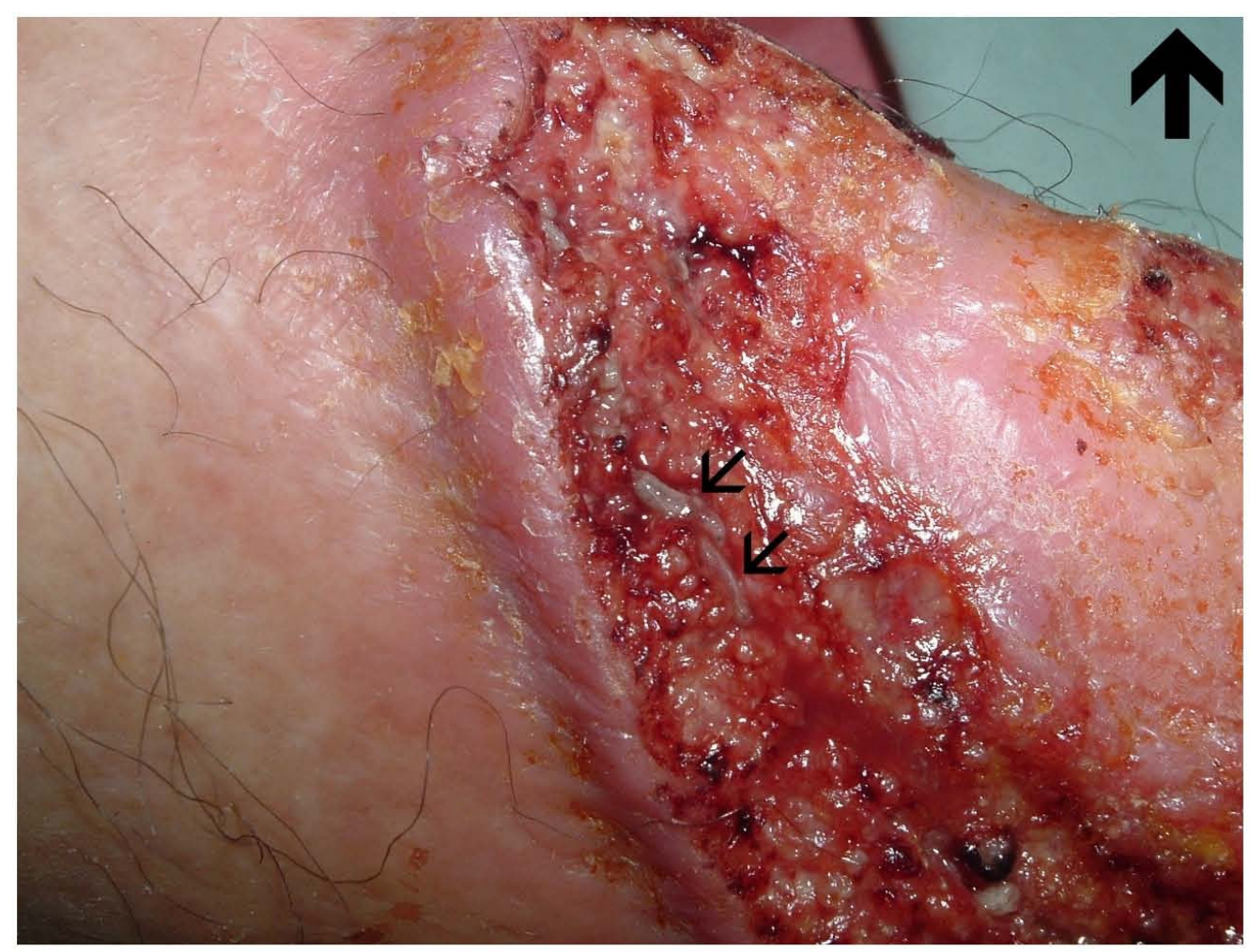

FIGURE 2. Close-up showing numerous larvae within the wound.

were found moving within the wound (Fig. 1 and close-up view in Fig. 2; the larvae are indicated by arrows). The larvae were analyzed and found to be Lucilia sericata (the green bottle blowfly). The lesion was diagnosed histopathologically as squamous cell carcinoma. The myiasis was treated by submerging the wound in a dilute permanganate potassium solution.

Wound myiasis occurs when fly larvae infest open wounds. It has been a serious complication of war wounds in tropical areas, and is sometimes seen in neglected wounds in most parts of the world. Predisposing factors include poor socioeconomic conditions, extremes of age, mental retardation, psychiatric illness, alcoholism, diabetes, and vascular occlusive disease.

This article should be cited as follows:

Namazi, M.R. and Fallahzadeh, M.K. (2009) Wound myiasis in a patient with squamous cell carcinoma. TheScientificWorldJOURNAL 9, 1192-1193. DOI 10.1100/tsw.2009.138. 


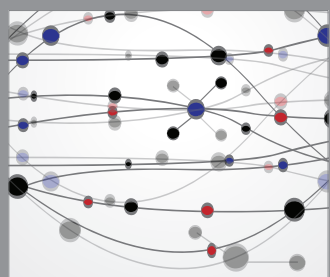

The Scientific World Journal
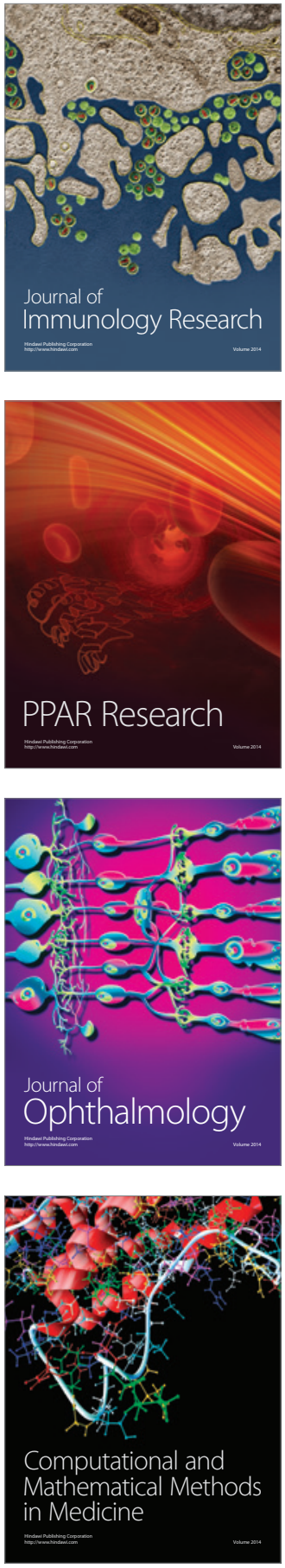

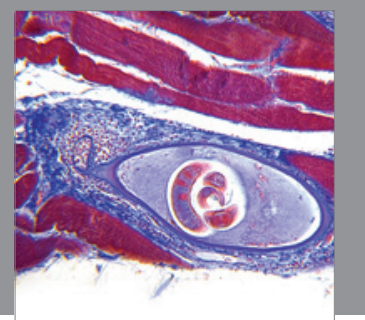

Gastroenterology

Research and Practice
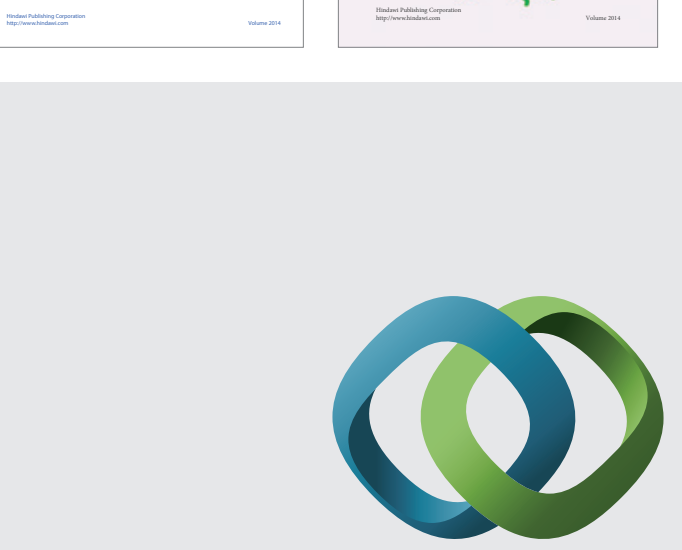

\section{Hindawi}

Submit your manuscripts at

http://www.hindawi.com
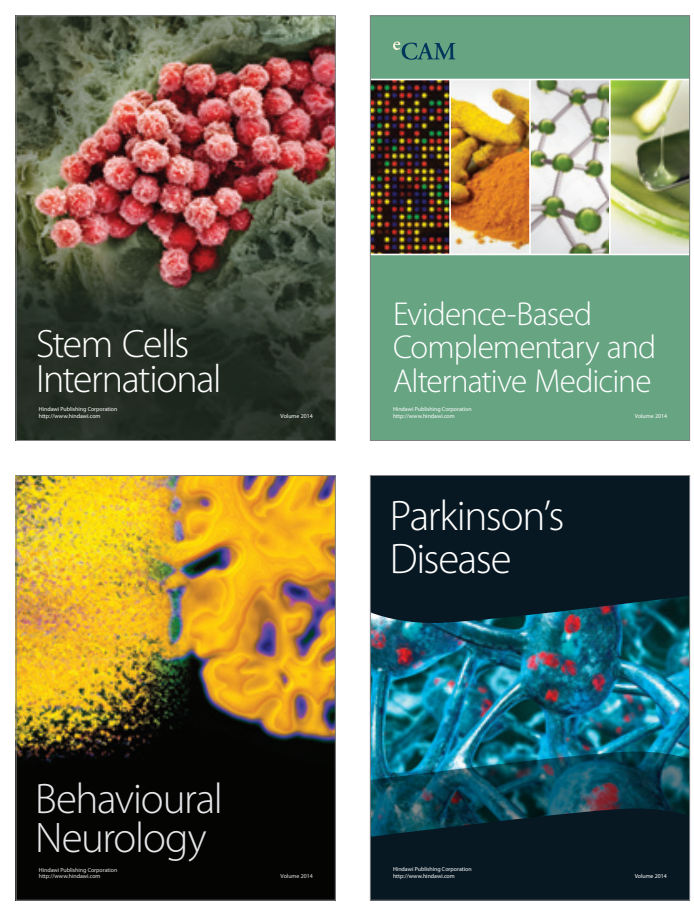

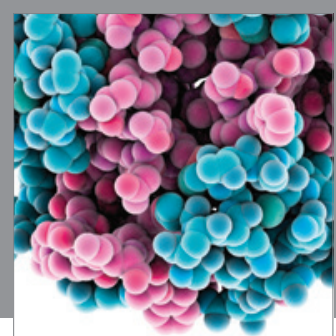

Journal of
Diabetes Research

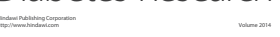

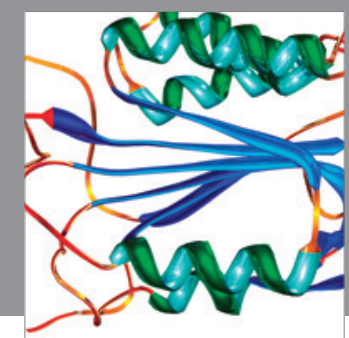

Disease Markers
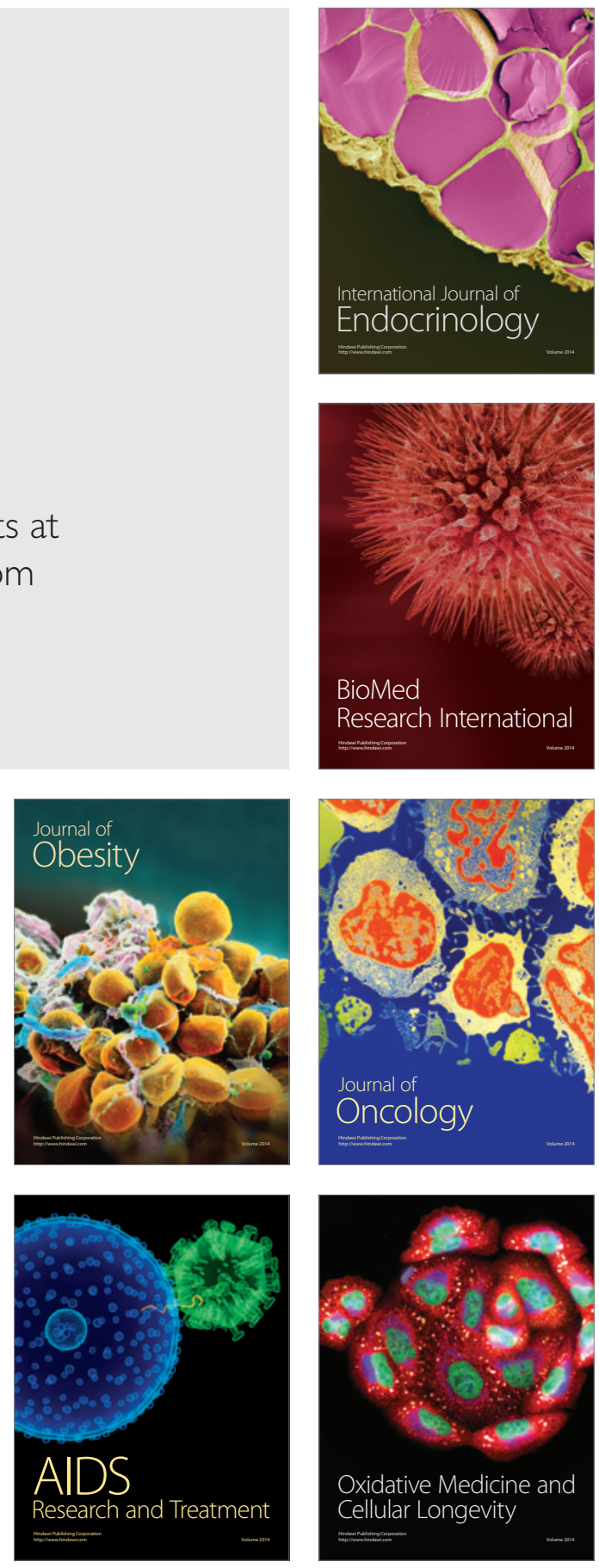